\title{
Damar İçi Madde Bağımlılığı Olan ve Madde Bağımlııı Olmayan Hastalar Arasında Hepatit C Virus (HCV) Genotiplerinin Dağılımı
}

\section{Distribution of Hepatitis C Virus (HCV) Genotypes Among Intravenous Drug and Non-Drug User Patients}

\section{Aylin ERMAN DALOĞLU'(ID), Ömür Mustafa PARKAN²(ID), Ali ERDOČAN³ (ID),} Bilal Olcay PEKER ${ }^{4}(I D)$, Rabia CAN SARINOǦLU ${ }^{5}(I D)$, İmran SAĞLIK ${ }^{6}(I D)$, Dilara INAN ${ }^{7}(I D)$, Mehmet Murat KULOC̆LU ${ }^{3}(I D)$, Derya MUTLU ${ }^{8}\left(\right.$ ID), Gözde ÖNGÜT ${ }^{9}\left(\right.$ ID), Dilek ÇOLAK ${ }^{8}$ (ID)

${ }^{1}$ Sağlık Bilimleri Üniversitesi Antalya Eğitim ve Araştırma Hastanesi, Tıbbi Mikrobiyoloji Laboratuvarı, Antalya, Türkiye.

${ }^{1}$ University of Health Sciences Antalya Training and Research Hospital, Medical Microbiology Laboratory, Antalya, Turkey.

2 Erciyes Üniversitesi Tıp Fakültesi, Tıbbi Mikrobiyoloji Anabilim Dalı, Kayseri, Türkiye.

2 Erciyes University Faculty of Medicine, Department of Medical Microbiology, Kayseri, Turkey.

${ }^{3}$ Akdeniz Üniversitesi Tıp Fakültesi, Psikiyatri Anabilim Dalı, Antalya, Türkiye.

${ }^{3}$ Akdeniz University Faculty of Medicine, Department of Psychiatry, Antalya, Turkey.

${ }^{4}$ İzmir Katip Çelebi Üniversitesi Atatürk Eğitim ve Araştırma Hastanesi, Tıbbi Mikrobiyoloji Laboratuvarı, İzmir, Türkiye.

${ }^{4}$ izmir Katip Çelebi University Atatürk Training and Research Hospital, Medical Microbiology Laboratory, Izmir, Turkey.

${ }^{5}$ Marmara Üniversitesi Pendik Eğitim ve Araştırma Hastanesi, Tıbbi Mikrobiyoloji Laboratuvarı, İstanbul, Türkiye.

${ }^{5}$ Marmara University Pendik Training and Research Hospital, Medical Microbiology Laboratory, Istanbul, Turkey.

${ }^{6}$ Uludağ Üniversitesi Tıp Fakültesi, Tıbbi Mikrobiyoloji Anabilim Dalı, Bursa, Türkiye.

${ }^{6}$ Uludağ University Faculty of Medicine, Department of Medical Microbiology, Bursa, Turkey.

${ }^{7}$ Akdeniz Üniversitesi Tıp Fakültesi, Enfeksiyon Hastalıkları Anabilim Dalı, Antalya, Türkiye.

${ }^{7}$ Akdeniz University Faculty of Medicine, Department of Infectious Diseases Antalya, Turkey.

${ }^{8}$ Akdeniz Üniversitesi Tıp Fakültesi, Tıbbi Mikrobiyoloji Anabilim Dalı, Viroloji Bilim Dalı, Antalya, Türkiye.

${ }^{8}$ Akdeniz University Faculty of Medicine, Department of Medical Microbiology, Division of Virology, Antalya, Turkey.

${ }^{9}$ Akdeniz Üniversitesi Tıp Fakültesi, Tıbbi Mikrobiyoloji Anabilim Dalı, Temel İmmünoloji Bilim Dalı, Antalya, Türkiye.

${ }^{9}$ Akdeniz University Faculty of Medicine, Department of Medical Microbiology, Division of Basic Immunology, Antalya, Turkey

Makale Atıfı: Erman Daloğlu A, Parkan ÖM, Erdoğan A, Peker BO, Can Sarınoğlu R, Sağlık $i$ ve ark. Damar içi madde bağımlıı̆ı olan ve madde bağımlısı olmayan hastalar arasında hepatit C virus (HCV) genotiplerinin dağılımı. Mikrobiyol Bul 2021;55(1):30-40.

\section{ÖZ}

Hepatit C virüsü (HCV) genotip dağılımı farklı hasta grupları ve farkıı bölgeler arasında yıllar içinde değişkenlik gösterebilmektedir. Damar içi madde bağımlıı̆ı (DiMB) prevalansının ülkemizde artış gösterdiği bilinmekte, fakat bu grupta HCV genotip dağııımını araştıran sınırlı sayıda çalışma bulunmaktadır. Bu veriler toplumdaki HCV epidemiyolojisindeki değişiklikleri izlemek açısından önemlidir. Sunulan çalışmada, DiMB nedeniyle ve DiMB dışındaki nedenlerle HCV ile enfekte olan hastalar arasında, beş yıllık HCV genotiplendirme sonuçlarının değerlendirilmesi amaçlanmıştır. Ocak 2014-Mart 2019 tarihleri arasında ayaktan ve yatarak takip edilen, HCV ile enfekte olduğu bilinen (HCV antikoru ve HCV RNA pozitif) 720 hastanın HCV genotiplendirmesi için laboratuvarımıza gönderilen plazma örnekleri analiz edilmiştir. 
Plazma örneklerinden HCV RNA ekstraksiyonu EZ1 Advanced (Qiagen, Almanya) otomatize ekstraksiyon sisteminde, EZ1 virüs mini kit v2.0 (Qiagen, Almanya) kullanılarak gerçekleştirilmiştir. Elde edilen ekstraktlardan, Rotorgene 6000 gerçek zamanlı polimeraz zincir reaksiyonu (Rt-PCR) (Qiagen, Almanya) cihazında, "HCV RNA Rt-quantitative 2.0 (NLM, İtalya)" kiti ile 5'-NCR ve core gen bölgesi çoğaltılarak amplikonlar elde edilmiştir. Genotiplendirmede, $5^{\prime} \mathrm{NCR}$ ve core bölgelerindeki varyasyonlara dayalı olarak HCV'nin 1, 2, 3, 4 ve 6 genotiplerini ve 1a, 1b, 2a/c, 2b, 3a, 3b, 3c, 3k 4a, 4b 4c/d, 4e, 4f, 4h, 5a, $6 \mathrm{a} / \mathrm{b}, 6 \mathrm{~g}, 6 \mathrm{f} / \mathrm{q}, 6 \mathrm{~m}$ ve $7 \mathrm{a}$ alt tiplerini ayırt edebilen in vitro ters hibridizasyon esaslı ticari bir "line prob assay (LIPA)" olan GEN-C 2.0 (NLM, italya) kiti kullanılmıştır. HCV ile enfekte DiMB olan 266 (\%93.2)'sı erkek (yaş ortalaması: $25 \pm 6.82$ ) ve DiMB olmayan 454 (\%51.3)'ü erkek (yaş ortalaması: $56.5 \pm 16.06$ ) hastanın HCV genotip dağılımı incelenmiştir. DiMB olan grupta sıklık sırasına göre; genotip 1a (\%54.1), genotip 3a (\%31.6), genotip 1b (\%5.3), genotip 4c/d (\%4.5), genotip 2b (\%1.5), genotip 4 (\%1.1), genotip 3 (\%0.7) görülmüş ve birer hastada genotip $1(\% 0.4)$, genotip $2 a / c(\% 0.4)$ ve miks genotip $(1+3 a)(\% 0.4)$ saptanmıştır. DiMB olmayan grupta ise sıklık sırasına göre; genotip 1b (\%62.3), genotip 1a (\%12.2), genotip 3a (\%9.5), genotip 1 (\%4), genotip 2a/c (\%1.1), genotip 4 (\%1) görülmüş ve birer hastada genotip $2 \mathrm{~b}(\% 0.2)$, genotip $4 \mathrm{c} / \mathrm{d}(\% 0.2)$, genotip $5 \mathrm{a}(\% 0.2)$, genotip $6 \mathrm{a} / \mathrm{b}(\% 0.2)$, genotip 6 $(\% 0.2)$ ve miks genotip (3+4) $(\% 0.2)$ saptanmıştır. Genotip 1a ve 3a, DiMB olanlarda anlamlı olarak ( $p<$ $0.00001, p<0.00001$ ) daha yüksek oranlarda saptanırken, genotip $1 \mathrm{~b}$ DiMB olmayanlarda anlamlı olarak $(p<0.00001)$ daha yüksek oranda saptanmıştır. Genotip 1a ve $3 a$, genç erkeklerde daha yaygın iken $(p<$ $0.00001, p=0.000163)$, genotip $1 b$ orta yaşlı kadınlarda $(p<0.00001)$ daha yüksek oranda saptanmıştır. Genotip $1 b(p=0.021)$ ve $3 a^{\prime} n ı n(p=0.012)$ görülme sıklığı yabancı uyruklularda Türk hastalara göre daha yüksek bulunmuştur. Yıllara göre HCV genotip dağılımı incelendiğinde genotip $1 \mathrm{~b}$ ve $1 \mathrm{a}$ oranlarının azalma, genotip 3a oranının artış yönünde olduğu gözlenmiştir. Sonuç olarak, bu çalışmada DiMB olanlar arasında HCV genotip dağılımının DiMB olmayan genel popülasyona göre farklı olduğu gözlenmiş, genotip 1a ve 3a'nın DiMB grubunda daha yaygın olduğu bulunmuştur. Ülkemizin diğer bölgelerinde olduğu gibi genel popülasyonda en sık genotip 1 b saptanmıştır. Genotip $3 a$, yıllara göre anlamlı oranda artmaktadır. Dünyanın farklı bölgelerinde var olan genotiplerin çalışma grubumuzda da saptanması, şehrimizde yaşayan yabancı uyruklu kişiler ve bölgemizin bir turizm merkezi olmasından kaynaklanabilir. Ayrıca, DiMB olanların sayısında yıllara göre bir artış olup olmadığının da araştııılması gereklidir.

Anahtar kelimeler: Damar içi madde bağımlılı̆ı; hepatit C virus; HCV genotip.

\section{ABSTRACT}

Genotype distribution of hepatitis C virus (HCV) can vary over the years between different patient groups and regions. The prevalence of intravenous drug users (IVDU) is known to increase in our country, yet there are a limited number of studies investigating the distribution of HCV genotypes in this group. These data are essential for monitorization of the changes in HCV epidemiology. The present study aimed to evaluate the five-year results of HCV genotyping among patients infected with HCV related to IVDU and unrelated to drug use. Plasma samples of 720 patients (HCV antibody, HCV RNA positive), which were sent to our laboratory for HCV genotyping between January 2014-March 2019 were analyzed. HCV RNA extraction from plasma samples was performed in the automated-extraction system of EZ1 advanced (Qiagen, Germany) using the EZ1 virus mini kit v2.0 (Qiagen, Germany). Amplicons were obtained by amplifying the $5^{\prime} \mathrm{NCR}$ and core gene region in the Rotorgene 6000 real-time PCR (Qiagen, Germany) device with the HCV RNA real-time quantitative 2.0 (NLM, Italy) kit. For the genotyping, a commercial line probe assay (LIPA) based on in vitro reverse hybridization GEN-C2.0 kit (NLM, Italy) which can distinguish 1, 2, 3, 4, 6 genotypes and $1 \mathrm{a}, 1 \mathrm{~b}, 2 \mathrm{a} / \mathrm{c}, 2 \mathrm{~b}, 3 \mathrm{a}, 3 \mathrm{~b}, 3 \mathrm{c}, 3 \mathrm{k}, 4 \mathrm{a}, 4 \mathrm{~b}, 4 \mathrm{c} / \mathrm{d}, 4 \mathrm{e}, 4 \mathrm{f}$, $4 \mathrm{~h}, 5 \mathrm{a}, 6 \mathrm{a} / \mathrm{b}, 6 \mathrm{~g}, 6 \mathrm{f} / \mathrm{q}, 6 \mathrm{~m}, 7 \mathrm{a}$ subtypes of HCV, based on variations in the $5^{\prime}-\mathrm{NCR}$ and core regions was used. HCV genotype distribution of 266 IVDU (93.2\%: male; median age: $25 \pm 6.82$ ) and 454 non-drug users (51.3\%: male; median age: $56.5 \pm 16.06)$ were examined. In order of frequency in the group with IVDU; genotype 1a, 3a, 1b, 4c/d, 2b, 4, 3 were observed and genotype 1, 2a/c and mixed genotype $(1+3 a)$ were detected in one patient. In the group without IVDU, in order of frequency; genotype $1 b$, $1 \mathrm{a}, 3 \mathrm{a}, 1,2 \mathrm{a} / \mathrm{c}$, 4 were observed and genotype $2 \mathrm{~b}, 4 \mathrm{c} / \mathrm{d}, 5 \mathrm{a}, 6 \mathrm{a} / \mathrm{b}, 6$ and mixed genotype $(3+4)$ were detected in one patient. Genotypes 1a and 3a were significantly higher in the IVDU group ( $<<0.00001$, $p<0.00001)$, while $1 b$ was significantly higher in patients without IVDU $(p<0.00001)$. Genotypes $1 a$ and $3 a$ were more common in young men $(p<0.00001, p=0.000163)$, while $1 b$ was higher in middleaged women $(p<0.00001)$. The incidence of genotypes $1 b(p=0.021)$ and $3 a(p=0.012)$ was higher in 
foreign nationals than the Turkish patients. When the HCV genotype distribution was examined by years, it was observed that the percentages of genotype $1 \mathrm{~b}$ and $1 \mathrm{a}$ were decreasing, while the percentage of genotype $3 a$ was increasing. As a result, in this study, HCV genotype distribution among IVDU was observed to be different from the general population without IVDU. It was found that genotypes $1 \mathrm{a}$ and $3 \mathrm{a}$ were more common in the IVDU group. As in the other regions of our country, genotype $1 \mathrm{~b}$ was found most frequently in the general population. Genotype 3a increases significantly compared to years. In our study, the determination of genotypes existing in different parts of the world may be due to the foreign nationals living in our city and our region is a tourism center. It is also necessary to investigate whether there is an increase in IVDU over the years.

Keywords: Intravenous drug users; hepatitis C virus; HCV genotype.

\section{Gíriş}

Dünya çapında yaklaşık 71 milyon insan kronik olarak Hepatit C virüsü (HCV) ile enfekte olup, her yıl 1.75 milyon yeni HCV enfeksiyonu gelişmekte ve yılda yaklaşık 400.000 ölüm HCV ile ilişkili siroz ve hepatoselüler karsinomdan kaynaklanmaktadır ${ }^{1}$. Dünya Sağlık Örgütü verilerine göre en fazla etkilenen bölgeler Doğu Akdeniz ve Avrupa olup, 2015 yılında HCV enfeksiyonunun prevalansı bu bölgelerde sırasıyla, \%2.3 ve \%1.5 olarak belirlenmiştir².

HCV, esas olarak intravenöz madde kullanımı, kan transfüzyonu, güvenli olmayan tıbbi girişimler ve cinsel temas yoluyla bulaşan bir virüstür. Damar içi madde bağımlılığı (DiMB) olanlar ortak enjektör paylaşımı gibi nedenlerle HCV enfeksiyonu için en yüksek riskli gruptur ${ }^{3}$.

HCV genotip dağılımı, DiMB gibi farklı bulaşma şekilleri ve coğrafi bölgeler ile ilişkili olarak farklılıklar göstermektedir ${ }^{4-6}$. HCV, yedi genotip ve 67 alt tip altında sınıflandırılmaktadır. Hindistan'dan bildirilen yeni bir çalışmada, sekiz genotip ve 19 yeni alt tip tanımlanmıştır ${ }^{7-9}$. Genotip dağılımının belirlenmesi, kronik HCV enfeksiyonunun tedavisi ve aşı geliştirme çalışmaları açısından klinik öneme sahiptir ${ }^{10}$.

HCV genotip dağılımı farklı hasta grupları ve farklı bölgeler arasında yıllar içinde değişkenlik gösterebilmektedir. DiMB prevalansının ülkemizde artış gösterdiği bilinmekte, fakat bu grupta HCV genotip dağılımını araştıran sınırlı sayıda çalışma bulunmaktadır ${ }^{11-13}$. Bu veriler toplumdaki HCV epidemiyolojisindeki değişiklikleri izlemek açısından önemlidir. Bu çalışmada, DiMB nedeniyle ve DiMB dışındaki nedenlerle HCV ile enfekte olan hastalar arasında, beş yıllık HCV genotiplendirme sonuçlarının değerlendirilmesi amaçlanmıştır.

\section{GEREÇ ve YÖNTEM}

Bu çalışma, Akdeniz Üniversitesi Tıp Fakültesi Etik Kurulu onayı ile gerçekleştirildi (Tarih: 13.05.2020 ve Karar no: 342).

\section{Hastalar}

Ocak 2014-Mart 2019 tarihleri arasında Akdeniz Üniversitesi Tıp Fakültesi Hastanesi (AÜTFH) Alkol ve Madde Bağımlıığı Araştırma ve Uygulama Merkezi (AMBAUM) ve Enfek- 
siyon Hastalıkları ve Klinik Mikrobiyoloji Bölümünde ayaktan ve yatarak takip edilen, HCV ile enfekte olduğu bilinen (HCV antikoru ve HCV RNA pozitif) 720 hasta çalışmaya alındı. Hastalara ait plazma örneklerinde AÜTFH Merkezi Laboratuvar Tıbbi Mikrobiyoloji Laboratuvarında yapılan HCV genotiplendirmesi sonuçları retrospektif olarak analiz edildi. Hastalara ait cinsiyet, yaş ve DiMB kullanımı bilgileri, hasta dosyaları incelenerek elde edildi.

\section{HCV Genotiplendirmesi}

Plazma örneklerinden HCV RNA ekstraksiyonu EZ1 advanced (Qiagen, Almanya) otomatize ekstraksiyon sisteminde, EZ1 virus mini kit v2.0 (Qiagen, Almanya) kullanılarak gerçekleştirildi. Elde edilen ekstraktlardan, Rotorgene 6000 gerçek zamanlı polimeraz zincir reaksiyonu (Rt-PCR) (Qiagen, Almanya) cihazında, HCV RNA Rt-quantitative 2.0 (NLM, İtalya) kiti ile 5'NCR ve core gen bölgesi çoğaltılarak amplikonlar elde edildi.

Genotiplendirmede, 5'-NCR ve core bölgelerindeki varyasyonlara dayalı olarak HCV'nin 1, 2, 3, 4 ve 6 genotiplerini ve 1a, 1b, 2a/c, 2b, 3a, 3b, 3c, 3k, 4a, 4b 4c/d, 4e, $4 \mathrm{f}, 4 \mathrm{~h}, 5 \mathrm{a}, 6 \mathrm{a} / \mathrm{b}, 6 \mathrm{~g}, 6 \mathrm{f} / \mathrm{q}, 6 \mathrm{~m}$ ve $7 \mathrm{a}$ alt tiplerini ayırt edebilen in vitro ters hibridizasyon esaslı ticari bir "line prob assay (LIPA)" olan GEN-C 2.0 (NLM, İtalya) kiti kullanıldı. Tüm analizler üretici firmaların önerilerine göre yapıldı. Farklı HCV genotiplerine özgü bantlar değerlendirilerek genotipler tanımlandı. Birden fazla genotipe karşılık gelen bantların olması durumu miks genotip olarak değerlendirildi.

\section{İstatistik}

Veriler, Windows SPSS, sürüm 22.0 (SPSS Inc., Chicago, Illinois, ABD) kullanılarak analiz edildi ve sonuçlar ortanca değerler \pm standart sapmalar (SD), sayı ve yüzde olarak sunuldu. Ki-kare testi ile gruplar arasındaki karşılaştırma yapıldı; $\mathrm{p}<0.05$ istatistiksel olarak anlamlı kabul edildi.

\section{BULGULAR}

HCV ile enfekte DiMB olan 266 (\%93.2 erkek; ortanca yaş= $25 \pm 6.82$ ) ve DiMB olmayan 454 (\%51.3 erkek; ortanca yaş= $56.5 \pm 16.06$ ) hastaya ait HCV genotip dağılımı Tablo I'de gösterilmiştir. DiMB olan grubun anlamlı olarak daha yüksek oranda erkek dağılımına sahip $(p<0.00001)$ genç hastalardan oluştuğu gözlenmiştir. Çalışma grubundaki 687 örnekte HCV genotip alt tipleri saptanmış, 31 örnekte HCV genotip alt tipleri saptanamamış, iki örnekte miks genotip bulunmuştur.

DiMB olan grupta sıklık sırasına göre; genotip 1a (\%54.1), genotip 3a (\%31.6), genotip 1 b (\%5.3), genotip 4c/d (\%4.5), genotip $2 b$ (\%1.5), genotip 4 (\%1.1), genotip 3 (\%0.7) görülmüş ve birer hastada genotip $1(\% 0.4)$, genotip $2 a / c(\% 0.4)$ ve miks genotip (1+3a) (\%0.4) saptanmıştır. DiMB olmayan grupta ise sıklık sırasına göre; genotip $1 \mathrm{~b}$ (\%62.3), genotip 1 a (\%12.2), genotip 3a (\%9.5), genotip 1 (\%4), genotip 2a/c (\%1.1), genotip 4 (\%1) görülmüş ve birer hastada genotip $2 b(\% 0.2)$, genotip $4 c / d(\% 0.2)$, genotip 5a (\%0.2), genotip $6 \mathrm{a} / \mathrm{b}(\% 0.2)$, genotip $6(\% 0.2)$ ve miks genotip $(3+4)(\% 0.2)$ saptanmıştır (Tablo I). 


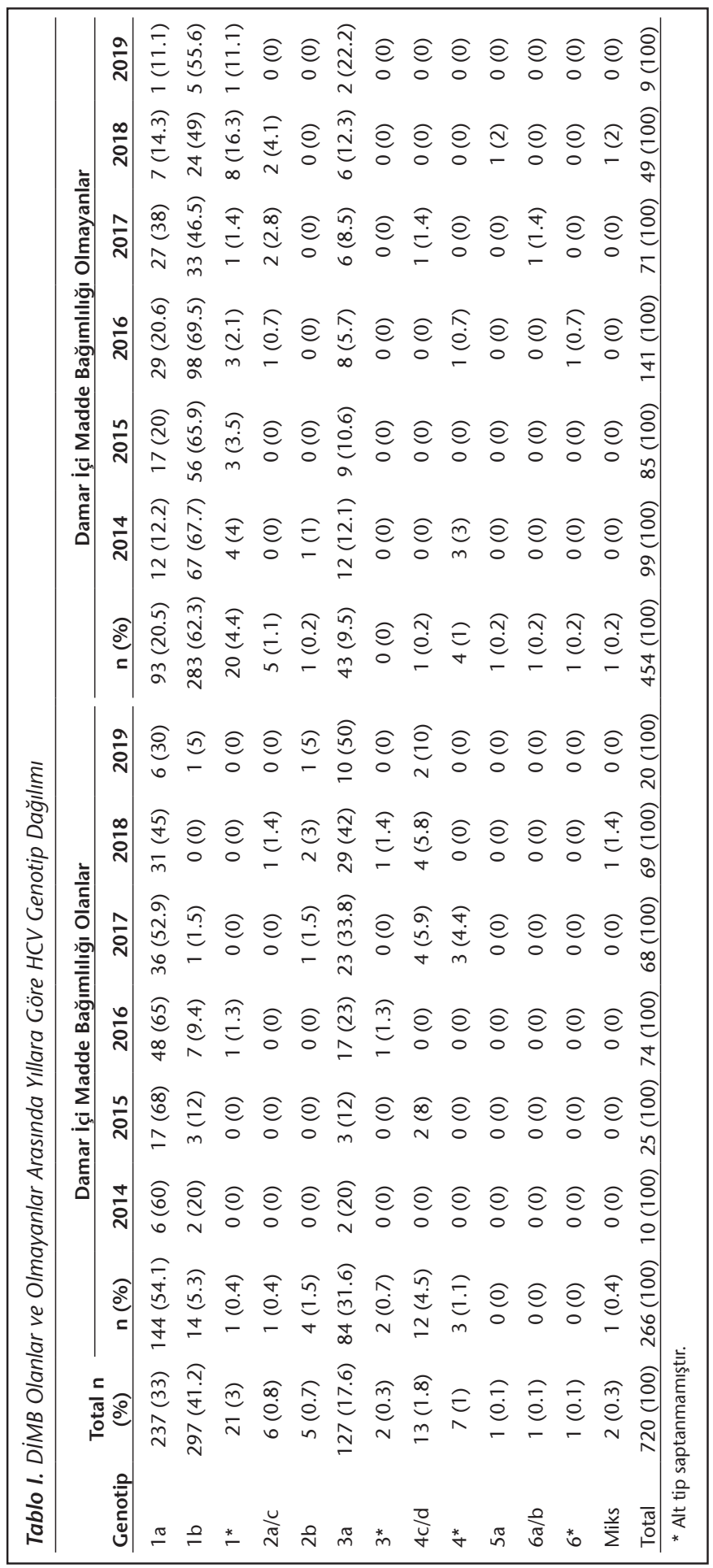




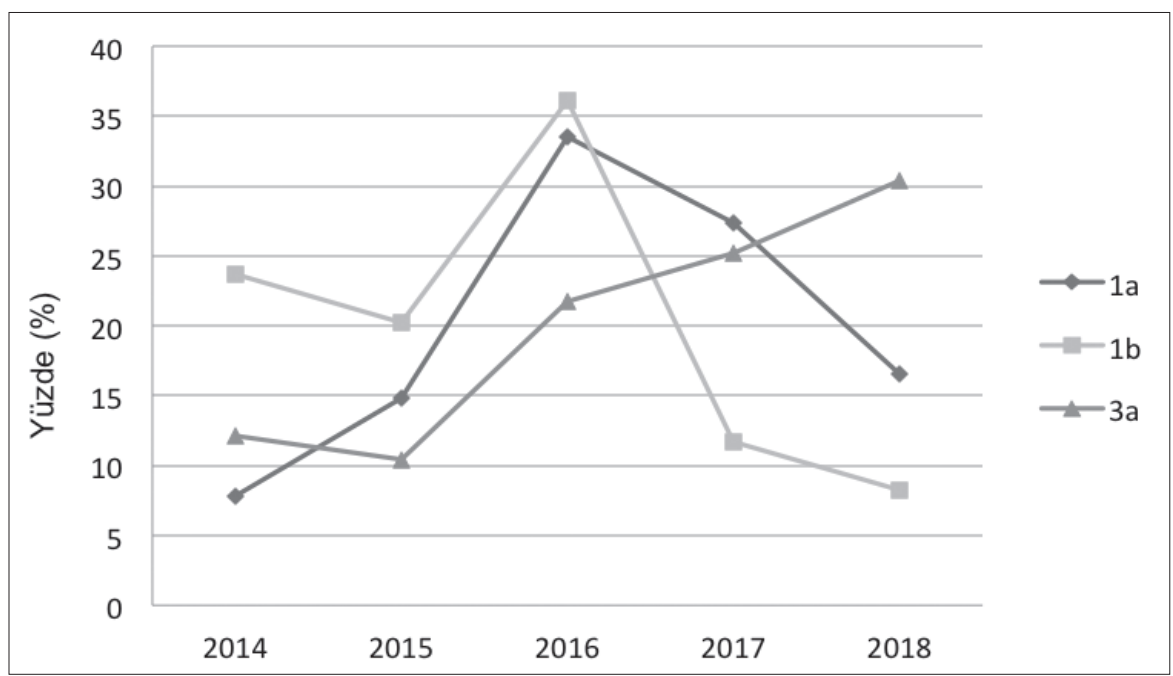

Şekil 1. Çalışma grubunda HCV genotip 1a, 1b ve 3a'nın 2014-2018 yılları arasındaki değişimi.

Genotip 1a saptananların (\%82.7 erkek; ortanca yaş: $29 \pm 16.29$ ) \%60.75'inde, genotip 3a saptananların (\%81.1 erkek; ortanca yaş: $27 \pm 10.96) \% 66$ 'sında ve genotip 1b saptananların \%4.7'sinde DiMB bulunmaktadır. Genotip 1b saptananların (\%51.9 kadın; ortanca yaş= $59 \pm 15.95) \% 95.3$ 'ünü DiMB olmayan hastalar oluşturmuştur. Genotip 1a ve 3a, DiMB olanlarda anlamlı olarak $(p<0.00001, p<0.00001)$ daha yüksek oranlarda saptanırken, genotip 1 b DiMB olmayanlarda anlamlı olarak $(p<0.00001)$ daha yüksek oranda saptanmıştır. Genotip 1 a ve $3 a$ genç erkeklerde daha yaygın iken $(p<0.00001, p=0.000163)$, genotip 1b orta yaşlı kadınlarda $(p<0.00001)$ daha yüksek oranda saptanmıştır.

Hasta grubunun 654 (\%90.8)'ü Türk (\%40.2'si DiMB), 66 (\%9.2)'sı yabancı uyruklu (DiMB, \%4.5) hastalardan oluşmuştur. Türk hastaların 261 (\%39.9)'inde genotip 1b, 232 (\%35.5)'sinde genotip 1a, 108 (\%16.5)'inde genotip 3a saptanırken, yabancı uyruklu hastaların 36 (\%54.5)'sında genotip 1b, 5 (\%7.6)'inde genotip 1a, 19 (\%28.8)'unda genotip 3a saptanmıştır. Genotip $1 b(p=0.021)$ ve 3a $(p=0.012)$ 'nın görülme sıklığı yabancı uyruklularda Türk hastalara göre daha yüksek bulunmuştur.

DiMB olan ve olmayan hastalar birlikte değerlendirildiğinde ve yıllara göre HCV genotip dağılımı incelendiğinde genotip 1 b ve 1 a oranlarının azalma, genotip 3a oranının artış yönünde olduğu gözlenmiştir (Şekil 1).

\section{TARTIŞMA}

Bu çalışmada, tedavi ve prognoz açısından önemli olan HCV genotip dağılımının belirlenmesi, DiMB nedeniyle ya da DiMB dışındaki nedenlerle HCV ile enfekte hastalar arasında dağılımdaki farklıııkların araştırılması amaçlanarak beş yıllık HCV genotiplendirme sonuçları değerlendirilmiştir. Türkiye'de DiMB olan HCV ile enfekte hastalarda 
genotip dağılımının araştıııldığı çalışmalar arasında en yüksek olgu sayısına $(n=266)$ sahip olan bu çalışma, aynı zamanda Antalya ilinden bildirilen DiMB grubunda HCV genotip dağılımının incelendiği ilk çalışmadır. Çalışmamızda sırası ile ilk üç sırada, DiMB olan hastalarda; genotip 1 a ve genotip $1 \mathrm{~b}$, genotip 3a ve DiMB olmayan hastalarda; genotip $1 \mathrm{a}$, genotip $1 \mathrm{~b}$ ve genotip $3 a$ saptanmıştır. DiMB olan hastalarda genel popülasyona göre genotip dağılımının değiştiği, genotip 1a ve 3a'nın daha yüksek oranlarda görüldüğü, genotip 1b’nin \%5.3'e kadar düştüğü gözlenmiştir.

Ülkemizde DiMB grubunda HCV genotip dağılımının incelendiği ilk araştırma 2016 yılında Üçbilek ve arkadaşları ${ }^{12}$ tarafından Adana, Mersin ve Kahramanmaraş illerinde 87 hasta ve LIPA yöntemi ile yapılmış; ilk üç sırada genotip 3, genotip 2 ve genotip 1 bulunmuştur. Kandemir ve arkadaşları ${ }^{13} 2017$ yılında Mersin ilinde DiMB olan 238 hastada LIPA yöntemi ile yaptıkları çalışmada, ilk üç sırada genotip 1a, genotip 3 ve genotip 2 HCV genotiplerini saptamış, genotip 3 saptanan grubun \%42.4'ünü genç erkek hastaların oluşturduğunu ve genotip 3 oranında yıllar içinde artış olduğunu belirtmişlerdir. Çaıışmamızda benzer olarak, genotip 3a bulunan hastaların \%66'sı DiMB olan genç erkek hastalardan oluşmakta ve genotip 3a yıllara göre anlamlı olarak artış göstermektedir. Çetin-Duran ve arkadaşları ${ }^{14} 2017$ yılında Adana'da 119 hastalık çalışma grubunda DiMB bulunan 12 hastanın dokuzunda genotip 3, üçünde genotip 2 saptadıklarını bildirmişlerdir. Yetim ve arkadaşları ${ }^{15} 2018$ yılında İstanbul'da DiMB olan 36 hastada sırasıyla, genotip 1a, genotip 3 ve genotip 2 saptamış, ancak genotipleme yöntemi hakkında bilgi vermemişlerdir. DiMB grubunda ülkemizden bildirilen çalışmalarda ilk üç sırada genotip 1, genotip 3 ve genotip 2'nin yer aldığı görülmektedir. Çalışmamızda DiMB grubunda genotip 1 ve genotip 3 saptanmış olmasına rağmen, genotip 2 ilk üç sırada yer almamıştır. DiMB olanlarda genotip 2'yi ilk sıralarda bildiren çalışmaların yapıldığı bölgelerde genotip 2 genel popülasyonda da ilk üç sırada yer almaktadır ${ }^{16}$. Antalya ilinde ise genel popülasyonda HCV genotip dağılımının araştırıldığı 2014 yılında bildirilen iki çalışmada genotip 2 ilk üç sırada yer almamıştır ${ }^{17,18}$. Buna göre; toplumda farklı bölgelerde genel popülasyonda baskın olan HCV genotipleri, DiMB gibi farklı hasta gruplarındaki genotip dağılımını etkileyebilir. Dünya genelinde DiMB olanlarda HCV genotip dağılımının incelendiği bir sistematik analizde; DiMB olanlarda genotip 3 ve 1a'nın genel popülasyona göre anlamlı olarak daha yüksek, genotip $1 b^{\prime}$ nin ise daha düşük prevalansa sahip olduğu bildirilmiştir ${ }^{6}$. Nazal yoldan madde kullanıcılarında, burunda ve kullandıkları aracı aletlerde HCV varlığının gösterilmiş olması ve nazal sekresyonlar ile HCV bulaşının gerçekleşebileceğinin belirtilmesi, "DiMB olan bireylerde nazal yol gibi farklı yollardan madde kullanımı farklı HCV giriş yollarına ve dolayısıyla farklı immünolojik süreçlere ve farklı genotip dağılımına yol açabilir mi?" sorusunu akla getirmektedir ${ }^{19}$.

HCV genotiplerinin genel popülasyondaki dağılımı ile ilgili olarak; Antalya'da Sağlık ve arkadaşları ${ }^{17} 2014$ yılında kronik HCV enfeksiyonu olan hastalarda LIPA yöntemi ile yaptıkları çalışmada ilk üç sırada genotip 1 b, genotip 1 a ve genotip 3a rapor etmişlerdir. Antalya'da yine 2014 yılında Çekin ve arkadaşları ${ }^{18}$, PCR ve dizi analizi yöntemleri ile 
ilk üç sırada genotip 1b, genotip 1a ve genotip 3 saptamışlardır. Çalışmamızda genel popülasyonda elde ettiğimiz sonuçlar ilimizde önceki yıllarda yapılan bu araştırmalarla uyumludur; çalışmamızda genotip 1b’nin, Sağlık ve arkadaşlarının çalışma bulgularına benzer şekilde ileri yaştaki kadın hastalarda daha sıklıkla görüldüğü ve genotip 3a'nın da yabancı uyruklularda Türk hastalara göre daha yüksek oranda bulunduğu gözlenmiştir. Ancak farklı olarak genotip 5 ve genotip 6 gibi daha önce bildirilmemiş genotipler ilk defa saptanmıştır. Genotip 3a oranı da ülkemizden bildirilen diğer oranlardan daha yüksek bulunmuştur. Türkiye'de, HCV genotip dağılımı ile ilgili 2010 yılı ve sonrasında gerçekleştirilen çalışmalarda; sıklık sırası değişkenlik göstermekle birlikte, başta genotip 1b olmak üzere 1a, 2, 3 ve 4 genotipleri ilk sıralarda yer almaktadır. Adana, Nevşehir, Adıyaman ve Şanlıurfa'da HCV genotip $2^{12,16,20-22}$ Kahramanmaraş başta olmak üzere, Antalya, Adana, Mersin, İstanbul ve İzmir'de HCV genotip $3^{12-18,23-26}$ Şanlıurfa ve Kayseri'de genotip 4'ün ${ }^{22,27}$ azımsanmayacak oranlarda olduğu dikkat çekmektedir. Ek olarak, İstanbul, Adana, Konya, Şanlıurfa ve İzmir'den HCV genotip 5 olguları ${ }^{14,22,23,28,29}$ Mersin, Diyarbakır ve Konya'dan da genotip 6 olgularının ${ }^{28-30}$ bildirildiği görülmektedir. LIPA yöntemi kullanılarak belirlenen HCV genotiplerinin dağılımı ile ilgili 2010 yılı ve sonrasında ülkemizden bildirilen çalışmalar, Tablo II'de belirtilmektedir.

Günümüzde HCV genotiplendirmesinde PCR ve dizi analizi yaygın olarak kullanılmakla birlikte, 5’NCR gen bölgesi ile birlikte core bölgesinin de kullanıldığı ve özellikle genotip 1 alt tip ayrımında güvenilir sonuçların alındığı LIPA yöntemi; maliyet ve uygulama kolaylığı açısından önemini korumaktadır. Miks genotiplerin ayrımında yeni nesil dizileme gibi ileri yöntemler kullanılabilir. Çalışmamızda bulunan genotip 1 sonuçları için özellikle genotip $1 \mathrm{a} / 1 \mathrm{~b}$ ayrımı açısından ve iki hastada saptanan miks genotiplere yönelik olarak dizi analizi, yeni nesil dizileme gibi ileri testler ekonomik nedenlerle uygulanamamıştır.

Sonuç olarak, bu çalışmada DiMB olanlar arasında HCV genotip dağılımının DiMB olmayan genel popülasyona göre farklı olduğu gözlenmiş, genotip 1a ve 3a'nın DiMB grubunda daha yaygın olduğu sonucu ortaya çıkmıştır. Ülkemizin diğer bölgelerinde olduğu gibi genel popülasyonda en sık genotip 1b olarak saptanmıştır. Genotip 3a yıllara göre anlamlı oranda artmaktadır. Dünyanın farklı bölgelerinde var olan genotiplerin çalışma grubumuzda da saptanması, şehrimizde yaşayan yabancı uyruklu kiş̧iler ve bölgemizin bir turizm merkezi olmasından kaynaklanabilir. Ayrıca, DiMB olanların sayısında yıllara göre bir artış olup olmadığının da araştırılması gereklidir.

\section{ETIK KURUL ONAYI}

Bu çalışma, Akdeniz Üniversitesi Tıp Fakültesi Etik Kurulu onayı ile gerçekleştirildi (Tarih: 13.05.2020 ve Karar no: 342).

\section{ÇIKAR ÇATIŞMASI}

Yazarlar bu makale ile ilgili herhangi bir çıkar çatışması bildirmemişlerdir. 


\begin{tabular}{|c|c|c|c|c|c|c|c|c|c|c|c|c|c|c|c|c|c|c|c|}
\hline & $\begin{array}{l}0 \\
\nabla\end{array}$ & $\begin{array}{l}\infty \\
\dot{0}\end{array}$ & $\hat{0}$ & 足 & $\stackrel{m}{\wedge}$ & $\bar{m}$ & 0 & $\hat{\imath}$ & 0 & $\stackrel{?}{\longrightarrow}$ & m̧ & $\begin{array}{l}n \\
0\end{array}$ & $\tilde{\sim}$ & $\stackrel{N}{N}$ & 0 & $\stackrel{\sim}{-}$ & $\stackrel{\sim}{r}$ & 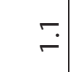 & \\
\hline & $\begin{array}{l}0 \\
m\end{array}$ & $\stackrel{\sim}{\sim}$ & $\begin{array}{l}q \\
\dot{\nabla}\end{array}$ & $\check{\check{C}}$ & $\hat{0}$ & $\dot{q}$ & $N$ & 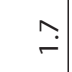 & $\begin{array}{l}0 \\
\infty \\
\infty \\
n\end{array}$ & $\stackrel{?}{\longrightarrow}$ & $\stackrel{\nabla}{m}$ & 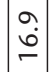 & $\stackrel{m}{m}$ & $\hat{\circ}$ & $\begin{array}{l}m \\
m \\
m\end{array}$ & $\left|\begin{array}{l}9 \\
\text { in }\end{array}\right|$ & $\stackrel{a}{-}$ & $\underset{m}{\stackrel{m}{m}}$ & \\
\hline & $\begin{array}{l}\circ \\
\text { i }\end{array}$ & $\overline{\mathrm{N}}$ & $\stackrel{0}{-}$ & $\tilde{m}$ & $\begin{array}{l}\stackrel{\circ}{\circ} \\
\stackrel{+}{*}\end{array}$ & $\stackrel{\square}{\circ}$ & $N$ & 0 & $\begin{array}{l}\infty \\
\stackrel{2}{ }\end{array}$ & $\dddot{n}$ & $\stackrel{\sim}{\sigma}$ & $\stackrel{n}{0}$ & $\stackrel{\infty}{m}$ & $\begin{array}{l}\stackrel{\circ}{+} \\
\end{array}$ & $\begin{array}{l}0 \\
\dot{n}\end{array}$ & $\overline{\mathrm{i}}$ & $\stackrel{m}{r}$ & $\stackrel{\leftrightarrow}{-}$ & \\
\hline & $\stackrel{0}{\frac{0}{\approx}}$ & $\overline{\mathrm{i}}$ & 0 & 0 & $\stackrel{\sim}{0}$ & 0 & 6 & $\cong$ & 0 & $\bar{m}$ & 0 & 0 & - & 0 & 0 & 0 & 0 & 0 & \\
\hline$\frac{\bar{t}}{\bar{g}}$ & 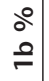 & $\begin{array}{l}\hat{\dot{D}} \\
\end{array}$ & $\underset{\infty}{n}$ & $\begin{array}{c}m \\
\tilde{n} \\
0\end{array}$ & $\hat{i}$ & 0 & 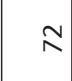 & $\begin{array}{l}\dot{v} \\
\dot{n} \\
\stackrel{1}{n}\end{array}$ & 0 & $\begin{array}{l}\infty \\
\dot{8} \\
\dot{8}\end{array}$ & $\stackrel{\nabla}{\dot{m}}$ & $\begin{array}{l}m \\
\dot{0} \\
\dot{n}\end{array}$ & $\begin{array}{l}0 \\
\dot{D} \\
\infty\end{array}$ & $\begin{array}{l}\infty \\
\stackrel{\infty}{m} \\
m\end{array}$ & 0 & 0 & 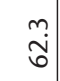 & $\stackrel{m}{i}$ & \\
\hline $\begin{array}{l}\tilde{n}_{1} \\
\overline{u_{n}} \\
\vdots\end{array}$ & $\begin{array}{l}\stackrel{0}{ } \\
\approx\end{array}$ & $\stackrel{.}{-}$ & $\stackrel{m}{i n}$ & $\stackrel{\hat{\dot{J}}}{\mathbf{f}}$ & $\tilde{n}$ & 0 & $\stackrel{\infty}{-}$ & $\begin{array}{l}\mathfrak{b} \\
\dot{m}\end{array}$ & $\hat{n}$ & $\stackrel{n}{\sim}$ & $\bar{f}$ & $\overline{\grave{n}}$ & $\stackrel{n}{m}$ & $\stackrel{m}{6}$ & $\overline{\dot{\sigma}}$ & 0 & $\tilde{\stackrel{n}{n}}$ & $\dot{\sim}$ & \\
\hline$\frac{5}{2}$ & $\begin{array}{l}\circ \\
-\end{array}$ & $\begin{array}{l}\infty \\
\dot{m}\end{array}$ & 0 & $\mid \begin{array}{l}\dot{v} \\
\dot{i}\end{array}$ & $\hat{\imath}$ & 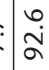 & 0 & $\stackrel{.}{-}$ & $\hat{\text { in }}$ & 0 & 0 & 0 & $\stackrel{\mathrm{i}}{\mathrm{v}}$ & $\stackrel{+}{\dot{r}}$ & 0 & 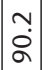 & $\stackrel{⿱ 亠 乂}{\dot{*}}$ & $\stackrel{+}{\circ}$ & \\
\hline 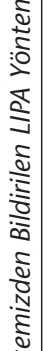 & 芒 & 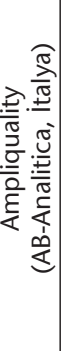 & 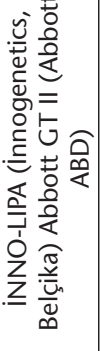 & 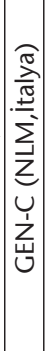 & 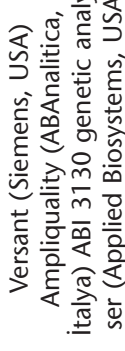 & 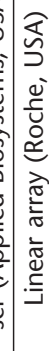 & 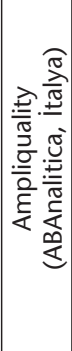 & 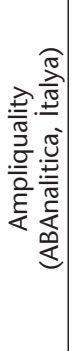 & 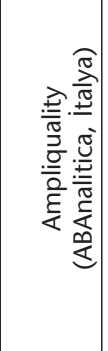 & 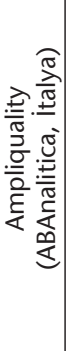 & 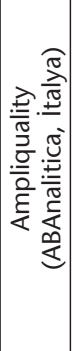 & 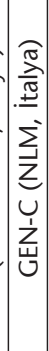 & 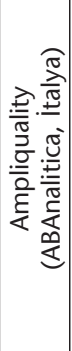 & 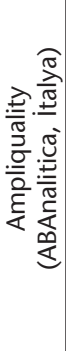 & 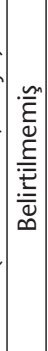 & 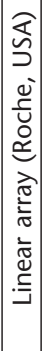 & 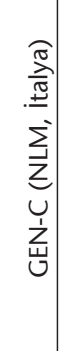 & 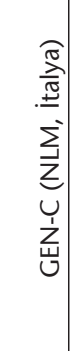 & 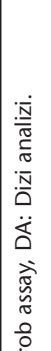 \\
\hline 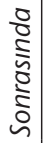 & 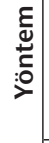 & ఏ & $\begin{array}{l}\text { ড̃ } \\
\vdots \\
\subseteq \\
\Xi\end{array}$ & $\leqq$ & $\begin{array}{l}\text { ఏ } \\
\text { ఏ }\end{array}$ & 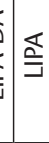 & $\leqq$ & $\leqq$ & $\leqq$ & $\leqq$ & ఏ & $\leqq$ & $\leqq$ & $\leqq$ & 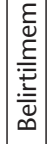 & 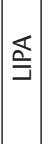 & $\leqq$ & 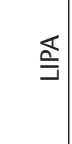 & 苍 \\
\hline 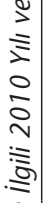 & $\begin{array}{l}\text { 意 } \\
\text { 心. }\end{array}$ & $\begin{array}{l}\cdot \frac{c}{5} \\
\frac{\bar{\omega}}{\Sigma} \\
\Sigma\end{array}$ & 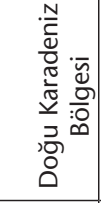 & $\mid \begin{array}{c}\frac{\pi}{\vec{\lambda}} \\
\frac{\vec{T}}{\frac{1}{\alpha}}\end{array}$ & 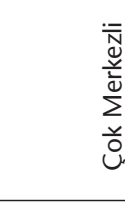 & 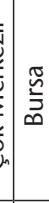 & 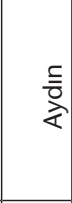 & 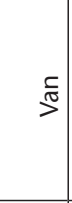 & 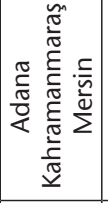 & 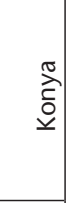 & $\begin{array}{l}\frac{5}{\bar{n}} \\
\frac{\bar{d}}{\Sigma}\end{array}$ & $\begin{array}{l}\underline{z} \\
\underline{\underline{L}} \\
\underline{\underline{n}} \\
\underline{\underline{n}}\end{array}$ & 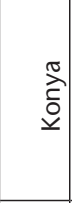 & $\begin{array}{l}\overline{\overline{0}} \\
\underline{\underline{c}} \\
. \underline{\underline{n}}\end{array}$ & \begin{tabular}{|l}
$\bar{z}$ \\
$\underline{0}$ \\
$\underline{\underline{n}}$ \\
$\underline{\underline{n}}$
\end{tabular} & 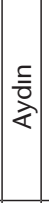 & $\frac{\text { T }}{\frac{\mathbb{\pi}}{\frac{\pi}{2}}}$ & $\begin{array}{l}\frac{\pi}{\frac{\pi}{\pi}} \\
\frac{\vec{T}}{2}\end{array}$ & 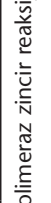 \\
\hline 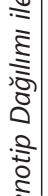 & 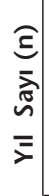 & 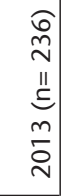 & 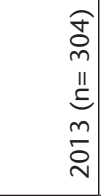 & 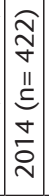 & 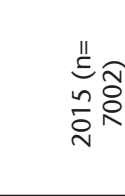 & 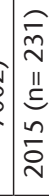 & 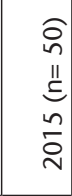 & 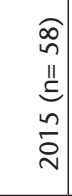 & 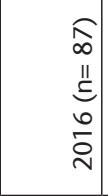 & 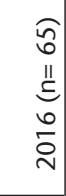 & 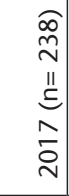 & 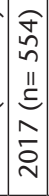 & 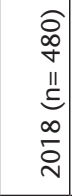 & 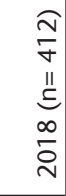 & 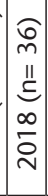 & $\mid \begin{array}{c}0 \\
\infty \\
\sim \\
11 \\
\vdots \\
\infty \\
0 \\
\sim\end{array}$ & \begin{tabular}{l}
\multirow{f}{f}{} \\
$\stackrel{2}{ }$ \\
$\stackrel{\text { II }}{5}$
\end{tabular} & 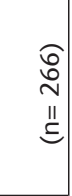 & 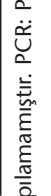 \\
\hline 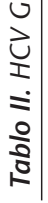 & $\begin{array}{l}\text { N } \\
\text { స్ }\end{array}$ & 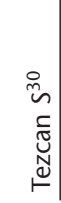 & 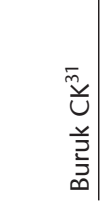 & 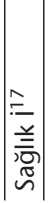 & 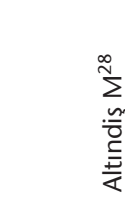 & 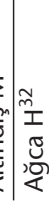 & $\begin{array}{l}\tilde{n} \\
\frac{1}{\bar{t}} \\
\frac{0}{\overline{0}} \\
\frac{\bar{L}}{2}\end{array}$ & 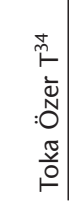 & 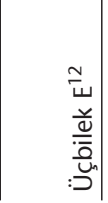 & 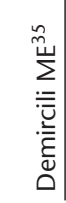 & 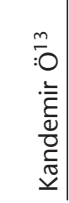 & 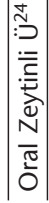 & 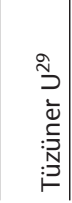 & 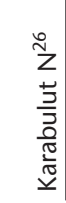 & 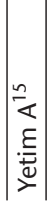 & 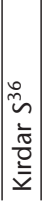 & 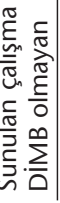 & 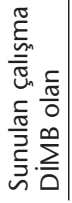 & 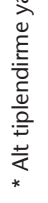 \\
\hline
\end{tabular}




\section{KAYNAKLAR}

1. World Health Organization (WHO). Global hepatitis report 2017. WHO 2018.

2. Mohd Hanafiah K, Groeger J, Flaxman AD, Wiersma ST. Global epidemiology of hepatitis $C$ virus infection: New estimates of age-specific antibody to HCV seroprevalence. Hepatology 2013; 57(4): 1333-42.

3. Degenhardt L, Peacock A, Colledge S, Leung J, Vickerman P, Stone J, et al. Global prevalence of injecting drug use and sociodemographic characteristics and prevalence of HIV, HBV, and HCV in people who inject drugs: a multistage systematic review. Lancet Glob Heal 2017; 5(12): e1192-e1207.

4. Gower E, Estes $\mathrm{C}$, Blach S, Razavi-Shearer K, Razavi H. Global epidemiology and genotype distribution of the hepatitis C virus infection. J Hepatol 2014; 61(1): 45-57.

5. Ruta $S$, Cernescu $C$. Injecting drug use: A vector for the introduction of new hepatitis $C$ virus genotypes. World J Gastroenterol 2015; 21(38): 10811-23.

6. Robaeys G, Bielen R, Azar DG, Razavi H, Nevens F. Global genotype distribution of hepatitis C viral infection among people who inject drugs. J Hepatol 2016; 65(6): 1094-103.

7. Smith DB, Bukh J, Kuiken C, Muerhoff AS, Rice CM, Stapleton JT, et al. Expanded classification of hepatitis $C$ virus into 7 genotypes and 67 subtypes: Updated criteria and genotype assignment web resource. Hepatology 2014; 59(1): 318-27.

8. Borgia SM, Hedskog C, Parhy B, Hyland RH, Stamm LM, Brainard DM, et al. Identification of a novel hepatitis $C$ virus genotype from Punjab, India: Expanding classification of hepatitis $C$ virus into 8 genotypes. J Infect Dis 2018; 218(11): 1722-9.

9. Hedskog C, Parhy B, Chang S, Zeuzem S, Moreno C, Shafran SD, et al. Open Forum Infectious Diseases Identification of 19 Novel Hepatitis C Virus Subtypes-Further Expanding HCV Classification. Open Forum Infect Dis 2019; 6(6).

10. Wyles DL, Gutierrez JA. Importance of HCV genotype 1 subtypes for drug resistance and response to therapy. J Viral Hepat 2014; 21(4): 229-40.

11. IIIhan MN, Arikan Z, Kotan Z, Tunçoğlu T, Pınarcı M, Taşdemir A, et al. Türkiye'de genel populasyonda tütün, alkol, madde kullanımı ve ilaç yanlış kullanımının prevalansı ve sosyo-demografik belirleyicileri. Noropsikiyatri Ars 2016; 53(3): 205-12.

12. Üçbilek E, Abayli B, Koyuncu MB, Midikli $D$, Gözüküçük $S$, Akdağ $A$, et al. Distribution of hepatitis $C$ virus genotypes among intravenous drug users in the Çukurova region of turkey. Turkish J Med Sci 2016; 46(1): 66-71.

13. Kandemir Ö, Gültekin O. Distribution of hepatitis $C$ virus genotypes in injection drug users with chronic hepatitis C. Turkiye Klin J Med Sci 2017; 37(1): 21-6.

14. Çetin Duran A, Kibar F, Çetiner S, Yaman A. Çukurova Üniversitesi Tıp Fakültesi Hastanesi'nde Hepatit C virus genotiplerinin ve HCV enfeksiyonu bulaş yollarının belirlenmesi. Den Biyol Derg 2017; 74(3): 201-10.

15. Yetim A, Şahin M. Hepatitis $C$ virus (HCV) infection in youth with illicit drug use: Sociodemographic evaluation and HCV genotype analysis. Klimik Derg 2018; 31(3): 190-4.

16. Öztürk $A B$, Doğan ÜB, Akçaer Öztürk N, Ozyazici G, Demir M, Akin MS, et al. Hepatitis $C$ virus genotypes in Adana and Antakya regions of Turkey. Turkish J Med Sci 2014; 44(4): 661-5.

17. Sağlik I, Mutlu D, Öngut G, İnan D, Öğünç D, Sarinoğlu Can R, et al. Distribution of hepatitis C virus genotypes among patients with chronic hepatitis $\mathrm{C}$ infection in Akdeniz University Hospital, Antalya, Turkey: a five-year evaluation. Mikrobiyol Bul 2014; 48(3): 429-37.

18. Çekin Y, Gür N, Çekin AH, Altuğlu I, Yazan Sertöz R. Antalya Eğitim ve Araştirma Hastanesinde kronik hepatit C hastalarinin genotip dagiliminin araştirilmasi. Mikrobiyol Bul 2014; 48(3): 484-90.

19. Aaron S, McMahon JM, Milano D, Torres L, Clatts M, Tortu S, et al. Intranasal transmission of hepatitis $C$ virus: virological and clinical evidence. Clin Infect Dis 2008; 47(7): 931-4.

20. Borçak $D$, Çağır Ü, Yalçıner A. Distribution of hepatitis $C$ virus genotypes and their association with serum alanine aminotransferases and quantitative serum HCV RNA Levels. Ankem Derg 2015; 29(1): 36-40. 
21. Akgün S, Tarhan G, Sayıner H, Akgün i, Kök S. Adıyaman ilinde hepatit C virüsü genotip dağılımının belirlenmesi. Ortadoğu Tıp Derg March 2017; 9(1): 1-5.

22. Cirit OS, Uzala Mızraklı A, Vurupalmaz Y, Gümüş HH, Özturhan H, Barış A. Genotyping distribution of hepatitis C virus in Şanlıurfa province and effect of Syrian patients. Viral Hepat J 2019; 25(2): 62-6.

23. Kaya S, Afşar I, Aksoy Gökmen A, Şener AG, Sayıner A. Evaluation of hepatitis C virus genotype results in İzmir Atatürk Training and Research Hospital. Viral Hepat J 2019; 25(2): 59-61.

24. Oral Zeytinli Ü, Muhterem Yücel F, Daldaban Dinçer Ş, Yanılmaz Ö, Aksaray S, Özdil K. Distribution of hepatitis $C$ virus genotypes in the region of İstanbul Northern Anatolian Association of Public Hospitals. Viral Hepat J 2017; 23(1): 10-3.

25. Kiriş̧̧i Ö, Çalışkan A, Alkış Koçtürk S, Erdoğmuş P, Gül M. Kahramanmaraşili hepatit C virüs ile enfekte bireylerde genotip dağılımı ve genotipin HCV-RNA yükü ve ALT-AST ilişkisi. Viral Hepatit Derg 2013; 19(2): 67-70.

26. Karabulut N, Alacam S, Yolcu A, Onel M, Agacfidan A. Distribution of hepatitis C virus genotypes in Istanbul, Turkey. Indian J Med Microbiol 2018; 36(2): 192-6.

27. Gökahmetoğlu S, Atalay MA, Kilinç A. Hepatit C virüs genotiplerinin pirosekanslama yöntemi ile belirlenmesi. Erciyes Tip Derg 2011; 33(2): 099-102.

28. Altindis M, Dal T, Akyar I, Karatuna O, Gokahmetoglu S, Tezcan Ulger S, et al. Six-year distribution pattern of hepatitis C virus in Turkey: a multicentre study. Medical Biotechnology 2016; 30(2): 335-40.

29. Tüzüner U, Saran Gülcen B, Özdemir M, Feyzioğlu B, Balkan M. Seven-year genotype distribution among hepatitis C patients in a city in the central Anatolia region of Turkey. Viral Hepat J 2018; 24(1): $12-7$.

30. Tezcan S, Ülger M, Aslan G, Yaraş S, Altıntaş E, Sezgin O, et al. Mersin ilinde hepatit C virüsü genotip dağılımının belirlenmesi. Mikrobiyol Bul 2013; 47(2): 332-8.

31. Buruk CK, Bayramoğlu G, Reis A, Kaklikkaya N, Tosun I, Aydin F. Doğu Karadeniz bölgesi hepatit C hastalarında hepatit C virüsü genotiplerinin belirlenmesi. Mikrobiyol Bul 2013; 47(4): 650-7.

32. Ağca H, Mıstık R, Kazak E. Güney Marmara bölgesinde hepatit C virüs genotiplerinin dağılımı. J Clin Anal Med 2015; 6(2): 190-2.

33. Kırdar S, Hadi Yaşa M, Aydın N, Gültekin Korkmazgil B, Barçın Öztürk Ş, Kurt Ömürlü i. The distribution of hepatitis C virus genotypes in patients with chronic hepatitis C infection. Meandros Med J 2015;16: 108-13.

34. Özer TT, Berktaş M, Yaman G, Erkoç R. Distribution of hepatitis C virus genotypes in patients with chronic hepatitis C infection in Eastern Turkey. Biomed Res 2015; 26(4): 697-701.

35. Demircili ME, Özdemir M, Feyzioğlu B, Baysal B. The efficiency of hepatitis C virus core antigen test in the diagnosis of hepatitis $C$ infection. Viral Hepat J 2016; 22(1): 18-22.

36. Kirdar S, Aydin N, Tiryaki Y, Ertugrul B, Coskun A, Bilgen M. Dynamics of HCV epidemiology in Aydin province of Turkey and the associated factors. APMIS 2018; 126(2): 109-13. 